\title{
An Examination of an Online Tutoring Program's Impact on Low-Achieving Middle School Students' Mathematics Achievement
}

\author{
Shanan Chappell, Pamela Arnold, John Nunnery, and Melva Grant \\ Old Dominion University
}

\begin{abstract}
The purpose of this mixed methods study was to determine the impact of synchronous online tutoring services on struggling middle school students' mathematics achievement. The online tutoring was provided as a response to intervention (RTI) Tier 3 support (intensive, individualized intervention) in schools implementing a school-wide mathematics program that addresses Tier 1 (high-quality classroom instruction) and Tier 2 (small group interventions). We employed quasi-experimental, within- and between-group designs to examine impacts for 119 students in two schools to measure the tutoring's impact on mathematics assessment scores. We also conducted qualitative analyses of student and tutor postsession commentary. The findings suggest that the tutoring contributed to statistically significant gains in student assessment scores postintervention. Online tutors' descriptions of their practice centered on ongoing progress monitoring of student learning, delivery of guided practice to students, the use of multiple explanations and representations of target concepts. Student perceptions of the online tutoring were predominately positive in nature.
\end{abstract}

\section{Introduction}

This article examines the impact of an online tutoring program on struggling middle school students' mathematics achievement, tutor descriptions of their online tutoring practices, and student perceptions of tutoring experiences as they occurred in real time. The tutoring was provided as a Tier 3 support to enhance the overall effectiveness of a school-wide mathematics reform effort, PowerTeaching math (PTm), a program funded under the U.S. Department of Education's Investing in Innovation scaleup initiative. This initiative is focused on the dissemination of research-based educational programming to high-need schools. PTm is grounded in research on cooperative learning, and focuses on teamwork among students within a structured cycle of instruction (Slavin, 1995). There is an extant body of research 
showing positive achievement effects for the instructional program, particularly among adolescent students (Nunnery, Chappell, \& Arnold, 2013). Within a response to intervention (RTI) framework, PTm embeds Tier 1 and Tier 2 supports through the provision of professional development and resources that focus on specific elements of primary and secondary prevention of learning difficulties, including (1) effective instructional strategies, (2) differentiation, (3) strategic grouping of students, and (4) progress monitoring (O’Connor \& Sanchez, 2011). Online mathematics tutoring was piloted in this context as a Tier 3 intervention for a subset of students who struggled the most with mathematics.

Fuchs et al. (2011) identify instructional explicitness as the first principle of effective intervention for students with mathematics difficulties. Schema theory suggests that learners develop recognition of mathematical problems across numerous experiences to abstract problem-solving strategies that may be generalized (Brown, Campione, Webber, \& McGilly, 1992). In other words, they develop schemas, or categories of problems that encompass similar types, and learn to apply increasingly effective strategies according to type. While typically developing students are able to do this more inductively, students who have accrued math deficits benefit from more explicit instruction facilitated by an expert who is able to provide clearly articulated schema-broadening instruction, with guided opportunities to recognize and learn the underlying mathematical structure of various problem types and specific transfer features (e.g., combinations of problem types) (Cooper \& Sweller, 1987; Fuchs et al., 2011; Kroesbergen \& Van Luit, 2003). Theoretically, individualized mathematics tutoring should provide increased opportunity for instructional explication, leading to broadened schema among students who are having difficulty constructing these independently. Individual mathematics tutoring as a Tier 3 intervention also provides students with mathematics difficulties with increased individualized progress monitoring. No method works for all students all the time; students who struggle with mathematics even within the context of an instructional environment that applies validated, research-based methods thus require individual tailoring. In these cases, systematic, ongoing progress monitoring facilitates the formulation of adjusted interventions that are effective for those students (Fuchs et al., 2011).

Although common characteristics of effective tutoring have been identified in the literature (Fashola, 1998), much of the focus has been on literacy rather than mathematics. With many school districts and funding agencies requiring research-based evidence on the effectiveness of strategies, the need for sound research on mathematics tutoring more specifically is clear. One earlier analysis of educational outcomes of mathematics tutoring revealed relatively large effect sizes in improving student achievement (Cohen, Kulik, \& Kulik, 1982). Huang (2013) compared tutoring influences on performance across countries, controlling for social and educational differences among them, and found that tutoring significantly increased national mean performance in mathematics. However, other researchers have concluded that not enough is known about the effect of tutoring on mathematics scores (Ritter, Barnett, Denny, \& Albin, 2009; Baker, Rieg, \& Clendaniel, 2006). Furthermore, some studies have found promising evidence to suggest that interactive online mathematics tutoring in particular may result in learning and achievement benefits for students (Beal, Walles, Arroyo, \& Woolf, 2007; Chappell, Nunnery, Pribesh, \& Hager, 2011; Nguyen \& Kulm, 2005), but less is known about how these programs function as Tier 3 interventions in contexts that carefully structure Tier 1 and 2 supports. This study explores how online mathematics tutoring impacted student achievement outcomes and perceptions in the context of a wider reform that provided primary and secondary supports, and functioned to augment that effort as a tertiary intervention.

\section{Literature Review}

\section{Mathematics Tutoring}

Instructional tutoring has an extensive history in American education. Tutoring services may be presented in a variety of formats and serve an array of purposes, though the overall goal of tutoring is generally to improve student achievement. The body of research on tutoring services is extensive and 
reported results of tutoring vary widely (Chappell et al., 2011). Research findings about the effectiveness of tutoring for improving mathematics performance have been similarly inconsistent (Bray, 2011; Huang, 2013; Rothman \& Henderson, 2011).

Although no specific model of effective supplemental tutoring has emerged from the literature to date, a number of successful programs have been identified, and these share some common characteristics, including well-trained, focused tutors; one-to-one tutoring experiences; a structured but flexible prescribed instructional plan; ongoing assessment to inform instructional efforts (Fuchs et al., 2011); and consistency in receiving tutoring services (Fashola, 1998; Wasik, 1998; Topping, 2000; Gordon, 2003; Sanderson, 2003). Fashola (1998) summarized the issue concisely: Programs that "provide greater structure, a stronger link to the school-day curriculum, well-qualified and well-trained staff, and opportunities for one-to-one tutoring seem particularly promising” (p. 55).

Other research offers additional insight about structural elements and tutor characteristics for effective mathematics tutoring programs. Effective mathematics tutors utilize their knowledge about mathematics content and curriculum when tutoring to generate multiple explanations and representations of the content for and with students, which is required for the development of mathematical understanding (Bray, 1999; Charalambos, Hill, \& Ball, 2011; Hiebert et al., 1997; Rothman \& Henderson, 2011). Effective tutors also know when and how to press learners, what resources to use, and how to use strategic questioning in lieu of telling or giving answers (Donnelly, 2013). Additionally, mathematics tutors who cultivate relationships with students and their teachers are more effective because in-school instructional activities and tutoring can be designed synergistically to build upon each other (Burns, Senesac, \& Symington, 2003; Rothman \& Henderson, 2011).

\section{Online Tutoring}

Instructional technology is becoming more and more prominent in educational settings, expanding beyond industry and higher education into K-12 environments. A systematic review conducted by Kulik (2003) indicated that instructional technology was becoming not only prominent in K-12 education but also a progressively more effective instructional strategy. Programs that offer online services may be able to provide benefits beyond just instructional support. For example, online tutoring programs can combine effective features of traditional tutoring services, such as research-based curricular resources and well-trained, qualified tutors, with synchronous supplemental instruction that can meet students where they are-academically and physically (Vasquez \& Slocum, 2012). Online, synchronous services that offer one-to-one, real-time tutoring can reach students in busy, urban areas as well as isolated, rural schools (Koerwer, 2007).

Over the past decade, online mathematics tutoring has emerged as an effective strategy to support student achievement in mathematics. A meta-analysis of out-of-school-time tutoring programs indicated that those agencies offering online mathematics tutoring had a larger effect size than agencies offering only face-to-face mathematics services (Chappell et al., 2011). A study by Beal et al. (2007) revealed that students showed significant improvement on mathematics problems after receiving online, interactive tutoring. The gains were experienced only in skills for which students received tutoring, as Beal et al. (2007) included problems with nontutored skills as control items in their analyses. These findings support other promising results that suggest that students benefit from online, real-time mathematics tutoring (Carnegie Learning, 2002; Nguyen \& Kulm, 2005). More importantly for the current study, results from such studies have revealed that students struggling with mathematics achievement benefit the most from online mathematics tutoring (Maloy, Razzaq, \& Edwards, 2014; Beal et al., 2007).

Research indicates that online mathematics tutoring should be consistent in order for participants to experience significant gains in achievement. However, the time investment required to achieve these gains is not substantial. Clark and Whetstone (2014) found that students who spent "as little as 50 minutes 
per week" (p. 465) participating in online mathematics tutoring experienced an effect size of .68equivalent to more than two thirds of a year's worth of improvement. Even more impressive are the results from a study of middle school students that found that more intensive tutoring at five hours per week for a 6-week period resulted in an average gain of an entire grade level in mathematics for participating students (eSchool News, 2009). In addition to employing tried-and-true, research-based traditional tutoring strategies, most online mathematics tutoring efforts also take place during the school day, often in a pull-out approach—a reality that baffles out-of-school-time tutoring proponents but has proven effective nonetheless.

\section{Relevance of the Study and Research Questions}

This study adds to the body of knowledge surrounding online mathematics tutoring by exploring how outcomes of tutored middle school students compare to those of students exposed only to their schools' business-as-usual mathematics instruction. The results are intended to provide sound, statistical evidence of the impact of mathematics tutoring, a need identified in the literature (Ritter et al., 2009, Baker et al., 2006). We addressed the following research questions in this study: (1) How does online mathematics tutoring affect mathematics scores of low achieving students? (2) What are students' perceptions of online mathematics tutoring services? (3) How do online mathematics tutors describe their pedagogical practices and student learning?

\section{Methods}

We employed a mixed methods approach, using quantitative methods to address the tutoring's impact on mathematics scores and qualitative methods to examine tutor and student commentary on the services. We used a quasi-experimental, pretest/posttest design (Leedy \& Ormrod, 2010) to analyze within-group changes in achievement scores for participating students, with separate analyses conducted for each school. Additionally, we conducted a causal comparative matched sample design to compare tutored students' achievement to that of nontutored students in School 1. Model-guided and inductivecoding qualitative techniques were used to analyze tutor descriptions of their online tutoring practice and student perceptions of the program (Zhang \& Wildemuth, 2009).

\section{Participants}

Students from two middle schools participated in this study. School 1 is a large rural school in southern Virginia, and School 2 is a large rural school in central Kansas. Both schools were also serving as pilot schools for a school-wide mathematics program, PTm, as part of an Investing in Innovation scaleup grant through the U. S. Department of Education. The tutoring occurred during Year 2 of the 5-year program.

All student participants in the study, both treatment and comparison, earned below passing scores on either the state standardized mathematics assessment for the 2012-2013 academic year (School 1), or failed the program's pretest assessment at the beginning of the 2013-2014 academic year (School 2). Forty-nine Grade 6 students from School 1 and 70 Grade 7 and 8 students from School 2 received tutoring during the 2013-2014 academic year. Students began receiving services in October 2013 and attended tutoring twice a week for 20 weeks. An additional 292 Grade 6 students in School 1 who did not receive tutoring services were included in the between-group analyses for that school.

Attendance records indicated that participants in School 1 attended an average of 28 sessions that were 30 minutes in length. On average, School 1 students received 14 hours of tutoring. Sixty tutors provided services for these students, with students working with six tutors on average throughout the program. Participants in School 2 attended an average of 38 sessions lasting 37 minutes per session, or about 23 hours of tutoring per student. A total of 61 tutors provided services for these students, with 
students working with an average of 8 tutors over the duration of the program. Tutoring services were provided twice a week in pull-out fashion during normal math class time for participating students.

All students in both schools were exposed to the school-wide mathematics program, PTm. In School 1, all students also received remediation in core subjects in a tiered RTI style. No other services were offered to nontutored students in School 1. In School 2, only those nontutored students with identified disabilities received additional mathematics services; other nontutored students did not receive any additional instruction in mathematics.

\section{Description of Services}

For this study, online mathematics tutoring was provided by Focus EduVation (FEV), a program whose services include interactive tutoring for K-12 students. Tutoring was provided in a synchronous, one-to-one online environment using chat, instant messaging, and virtual whiteboard technology. Grounded in principles of effective remediation for students with mathematics difficulties, the program focuses on individualized progress monitoring to design and adjust tailored interventions (Fuchs et al., 2011). Diagnostic assessments were administered to participating students before tutoring began to allow program and school personnel to develop individualized learning objectives for each student. Based on these learning objectives, a learning plan was created for each student. Learning plans were aligned with the school's curricular standards and scope and sequence to ensure that the services met the student's and school's specific needs. The learning plans served as the foundation for the tutoring but were flexible enough to accommodate minor changes over the duration of the program. Overall, the tutoring was intended to provide a differentiated, engaging environment where skills were enhanced through sharing of curricular materials, practice problems and visuals, and graphic features to aid communication and collaboration between students and tutors. Shared communication was focused on providing students who struggle with mathematics with expert instructional explication to promote lateral transfer and schema development (Brown et al., 1992; Gick \& Holyoake, 1983). Tutors providing services were required to have a minimum of a 4-year degree and 2 years teaching or tutoring experience, and underwent background checks to ensure a safe environment. In-session assessments allowed tutors to assess student progress by specific skill in a formative manner, and posttests allowed for an examination of students' overall growth.

\section{Data Sources}

We used scores from the 2013 and 2014 administrations of the Virginia Standards of Learning (SOL) assessment for participating students as pretest and posttest for School 1 and program-administered pretests and posttests for School 2 (state-level assessments were unavailable for School 2 due to a moratorium on testing in 2014).

Additionally, we examined tutor-generated summaries of each online tutoring session, as well as responses to open-ended items from students that solicited their perceptions of the tutoring services. These summaries and responses were used to explore themes related to tutor practices and student perceptions of the tutoring they received. These data were collected by the tutoring agency and provided to us through a data use authorization with the two schools.

\section{Analytic Approach}

We conducted paired samples $t$-tests for each school using pretreatment and posttreatment scores to determine within-group changes in each school. Tutored students in School 1 were also matched with nontutored students (see matching procedures below), and between-group differences were examined using an analysis of covariance (ANCOVA). We also computed Cohen's $d$ within-group effect-size 
estimates for tutored and comparison students using the correction for dependence method (Morris \& Deshon, 2002).

Matching procedures. The propensity score matching approach (Guo \& Fraser, 2010) was used to match the Grade 6 tutored students in School 1 with nontutored students. A total of 407 students were enrolled in Grade 6 mathematics and were included in the initial matching procedures. Sixty-six students were removed from the sample because they did not have achievement scores for both 2013 and 2014. Ultimately, 341 students were included in the matching procedures, with 49 in the treatment group and 292 in the comparison group.

Propensity scores were estimated by the predicted probabilities of a logistic regression model (Guo \& Fraser, 2010) with the tutoring status as the criterion variable and the following covariates serving as predictor variables: minority status, economically disadvantaged status, disability status, student in recovery status, gender, and 2013 SOL scaled score. Student demographics were those assigned by the division/state. Descriptions are as follows: minority status, all students not categorized as White (Black or African American, Hispanic, and multiracial); economically disadvantaged, students eligible for free or reduced-price lunch; disability status, any student identified with a learning, physical, emotional, behavioral, or mental disability; and student in recovery status, any student who has participated in a remediation program.

The overall model fit of the logistic model was supported, $\chi^{2}(8, N=341)=14.76, p=.07$. The 1 to-2 nearest neighbor matching approach (Guo \& Fraser, 2010) was utilized to match each tutored student with two nontutored students with the smallest absolute differences of the estimated propensity scores. As a result, 49 tutored students were matched with 98 nontutored students.

Prior to the matching procedure, the tutored and the nontutored groups differed significantly on the minority, economically disadvantaged, recovery, and 2013 achievement scores predictors (see Table 1). After the matching procedure, the tutored students were statistically equivalent to the nontutored students on all covariates except the recovery predictor and the baseline achievement score, with the nontutored group having more students in recovery and a higher mean 2013 SOL scaled score (see Table 2). The overall group equivalencies improved with the propensity score matching, and we proceeded with the analyses using the recovery indicator and the 2013 mean SOL scaled score as covariates in our ANCOVA to control for the pretreatment differences.

Table 1 Covariate Descriptive Statistics and Equivalency Checks by Tutoring Status Before Matching $(n=341)$

\begin{tabular}{llll} 
Covariate & $\begin{array}{l}\text { Tutored } \\
\text { (overall } n=49)\end{array}$ & $\begin{array}{l}\text { Nontutored } \\
(\text { overall } n=292)\end{array}$ & $\begin{array}{l}\text { Equivalency } \\
\text { analysis }\end{array}$ \\
\hline Minority & 32 & 120 & $\chi^{2}=9.96^{*}$ \\
Economically disadvantaged & 37 & 161 & $\chi^{2}=7.15^{*}$ \\
Disability & 8 & 43 & $\chi^{2}=.09$ \\
Recovery & 32 & 63 & $\chi^{2}=39.93^{* *}$ \\
Female & 27 & 155 & $\chi^{2}=.07$ \\
2013 SOL Scaled Score & 49 & 292 & $t=15.72^{* *}$ \\
\hline
\end{tabular}

*Statistically significant at the .01 level

**Statistically significant at $p<.001$ 
Table 2 Covariate Descriptive Statistics and Equivalency Checks by Tutoring Status After Matching $(n=147)$

\begin{tabular}{llll}
\hline Covariate & $\begin{array}{l}\text { Tutored } \\
\text { (overall } n=49)\end{array}$ & $\begin{array}{l}\text { Nontutored } \\
\text { (overall } n=98)\end{array}$ & $\begin{array}{l}\text { Equivalency } \\
\text { analysis }\end{array}$ \\
\hline Minority & 32 & 59 & $\chi^{2}=0.36$ \\
Economically disadvantaged & 37 & 74 & $\chi^{2}=0.00$ \\
Disability & 8 & 21 & $\chi^{2}=0.54$ \\
Recovery & 32 & 44 & $\chi^{2}=5.45^{*}$ \\
Female & 27 & 45 & $\chi^{2}=1.10$ \\
& 49 & 98 & $t=5.42^{* *}$ \\
\hline
\end{tabular}

*Statistically significant at the .05 level

**Statistically significant at $p<.001$

To address Research Questions 2 and 3, we analyzed 84 tutor-generated session summaries and 84 postsession commentaries by students across both schools. These data were analyzed using NVivo, a qualitative data analysis software program that enables users to create a flexible node structure where similar data may be coded throughout analysis to assist in the iterative construction of categories and themes (Patton, 2002). Both model-guided and inductive coding were employed in the analysis (Zhang \& Wildemuth, 2009). Analysis of tutor summaries of online sessions was guided by practice components of the tutoring model and the literature on pedagogical strategies for mathematics remediation. Student comments were analyzed to identify students' emic perceptions of the program. The codebooks developed for analyses of tutor and student comments appear in Appendix A.

Several strategies were employed to enhance the trustworthiness of findings emerging from this process: (a) two researchers analyzed each data source; (b) researchers met frequently to establish, clarify, and revise codes and categories; (c) an electronic audit trail was maintained; (d) a program model provided referential adequacy; and (e) findings were contextualized within the broader literature on mathematics learning and pedagogy (Shenton, 2004). These strategies extend the credibility, confirmability, transferability, and dependability of the findings. Further, representativeness indices were calculated to provide information about the extent to which themes emerged across individuals, and how prevalent each was throughout the discourse. These indices provided context related to the number of sources with statements coded to each theme at least once, and the salience of themes in terms of the number of references generated across participants accruing to a single code.

\section{Results}

\section{Within-Group Outcomes in Schools 1 and 2}

Scores on the program-administered pretests indicated that participating students in each school had below-passing averages. School 1 had no students with passing averages on pretest assessments and no students with passing scaled scores on the prior year's mathematics SOL. School 2 also had no students with passing averages on the program administered pretest assessments.

At the end of the program, 30 (61.2\%) of the School 1 students had passing scaled scores on the mathematics SOL. Before exposure to the program, the mean score for participating students in School 1 on the 2013 Virginia SOL mathematics assessment was 383.08, below the proficiency cut score. The average score on the Virginia 2014 SOL mathematics assessment for the same students in School 1 was 405.96, which is above the 400 cut score for proficiency in Virginia (Virginia Department of Education, 2012). Within-group differences from pre-intervention to postintervention for School 1 showed 
significant improvement in scores for the group, with a mean improvement of 22.88 points $(t=5.99, p<$ .001). Within-group effect-size estimates for School 1 were $d=+0.95$ for tutored students.

At the end of the program, 15 (30\%) of the tutored students in School 2 had passing averages on program-administered posttests. Although the posttest average for School 2 was below the passing level $(M=53.03)$, students in School 2 did show significant improvement in achievement, with a mean gain of 26.16 points $(t=10.11, p<.001)$. The within-group effect-size estimate for tutored students in School 2 was $d=+1.47$.

Table 3 reports pretreatment and posttreatment means, mean differences, and probability values for both schools. Figures 1 and 2 illustrate the gains in achievement for each school.

Table 3 Paired-Samples Results for Mean Outcome Scores by School

\begin{tabular}{|c|c|c|c|c|c|}
\hline & $n$ & $\begin{array}{l}\text { Pretest } \\
\text { mean } \\
(S D)\end{array}$ & $\begin{array}{l}\text { Posttest } \\
\text { mean } \\
(S D)\end{array}$ & $\begin{array}{l}\text { Mean } \\
\text { difference }\end{array}$ & $p$ \\
\hline School 1 & 49 & $\begin{array}{r}383.08 \\
(11.31)\end{array}$ & $\begin{array}{r}405.96 \\
(26.36)\end{array}$ & 22.88 & $<.001$ \\
\hline School 2 & 50 & $\begin{array}{l}26.87 \\
(11.68)\end{array}$ & $\begin{array}{l}53.03 \\
(16.76)\end{array}$ & 26.16 & $<.001$ \\
\hline
\end{tabular}

Figure 1. Comparison of pre- and posttreatment scores for students receiving services in School 1.

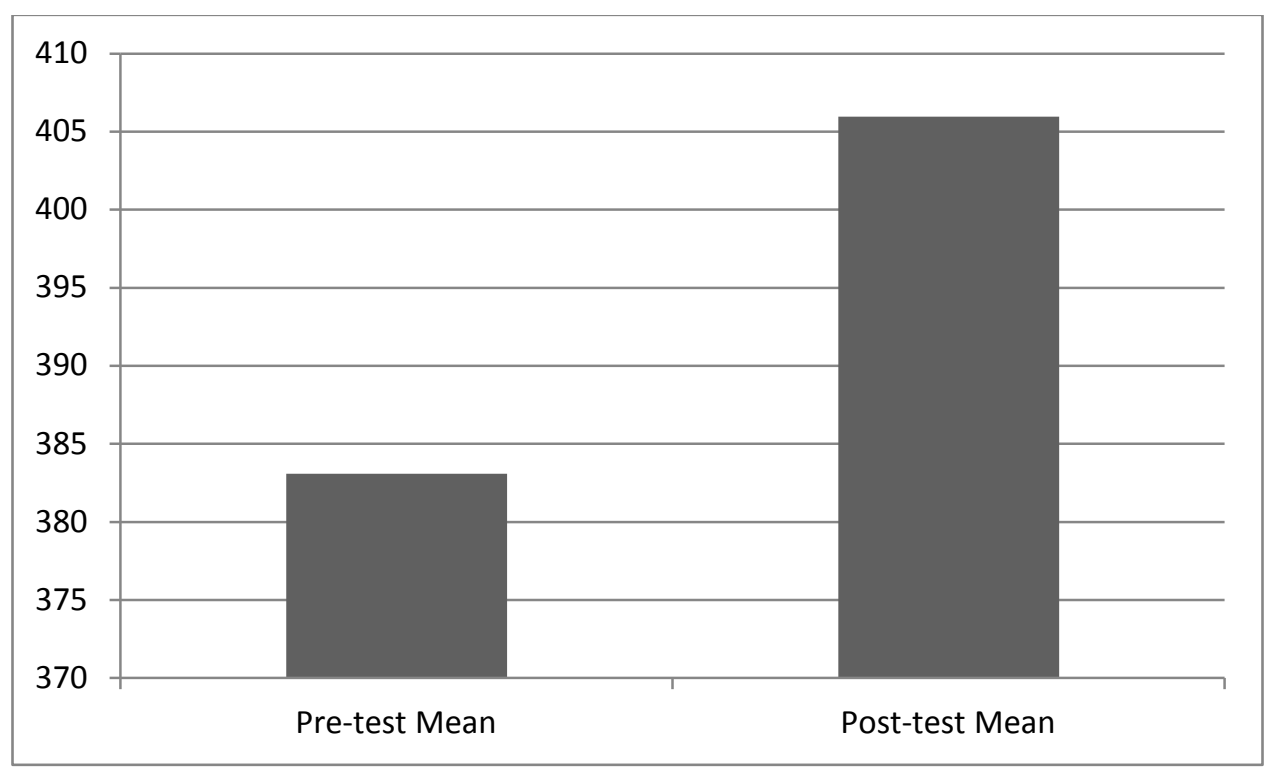


Figure 2. Comparison of pre- and posttreatment scores for students receiving services in School 2.

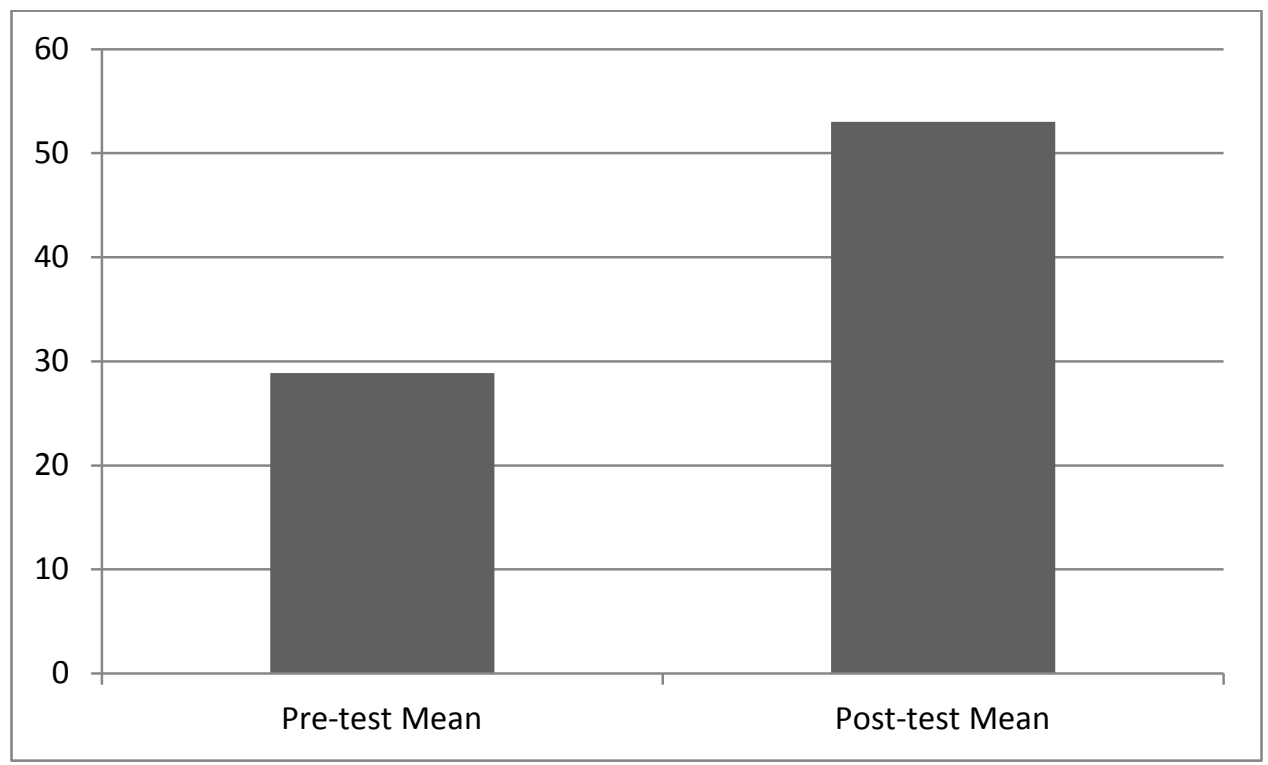

\section{Between-Group Outcomes in School 1}

The ANCOVA indicated nonsignificant differences between the 2014 SOL scaled posttest scores for the tutored group and the matched, nontutored group, $F=1.66(1,144), p=.20$. This means that the nontutored group's statistically significantly higher baseline score advantage was narrowed postintervention, after controlling for recovery status and 2013 SOL scaled score. It is worth noting, however, that both groups had statistically significant within-group increases in scores from pretest to posttest, indicating significant growth for both groups (within-group results for comparison group: $t=$ 2.35, $p=.02$ ). Within-group effect-size estimates for School 1 were $d=+0.95$ for tutored students, and $d$ $=+0.24$ for nontutored students. Table 4 reports between-group comparisons by treatment status.

Table 4 Analysis of Covariance for Outcome Scores for School 1

\begin{tabular}{|c|c|c|c|c|c|}
\hline & $\begin{array}{l}\text { Pretest } \\
\text { mean* }(S D)\end{array}$ & $\begin{array}{l}\text { Observed } \\
\text { posttest } \\
\text { mean }(S D)\end{array}$ & $\begin{array}{l}\text { Adjusted } \\
\text { posttest } \\
\text { mean }(S E)\end{array}$ & $F$ & $p$ \\
\hline Tutored students & $\begin{array}{l}383.08 \\
(11.31)\end{array}$ & $\begin{array}{l}405.96 \\
(26.36)\end{array}$ & $\begin{array}{l}409.28 \\
(5.74)\end{array}$ & \multirow[b]{2}{*}{1.66} & \multirow[b]{2}{*}{.20} \\
\hline Comparison students & $\begin{array}{l}406.90 \\
(40.48)\end{array}$ & $\begin{array}{l}424.20 \\
(65.95)\end{array}$ & $\begin{array}{l}422.54 \\
(8.26)\end{array}$ & & \\
\hline
\end{tabular}

*Pretest mean difference between tutored and comparison students was statistically significant at the .001 level. 


\section{Tutoring Descriptions}

Tutor-session log data across both sites revealed that almost all tutors discussed implementing pre- and postassessments of student learning during each session, and analyzed these data to guide the instruction provided in the session. Many of the tutors also provided descriptions of their reflections on student learning during independent practice, and provided individualized differentiation as needed. Almost all tutors described the delivery of guided practice to students, and many discussed the use of multiple explanations and representations of target concepts. Tutors described interventions focused on accessing prior knowledge, modeling ("showed him how to multiply the decimal number with example"), explaining the steps in mathematical processes ("explained all the five steps to find the square root of the irrational numbers"), identifying both process and operational errors ("another problem of similar kind was worked by the student with minor mistakes, which she corrected on tutor's advice"), and scaffolding through the use of questions or prompts ("tutor helped the student by providing hints to get the right answer”).

Tutor reflections on student learning were prevalent throughout the summaries and included articulation of student's postlesson content mastery, session scores, and identification of prior knowledge that was necessary for success. Identification of various types of student difficulties as well as leverage points for further instruction were often present, as exemplified by the following tutor comments: "The student struggled with multiplying the decimals, but corrected himself and was fast while learning," and "Student was able to translate the given image and could reflect the image over different axis on the coordinate plane with ease.”

\section{Student Perceptions}

Analysis of student postsession commentary on the tutoring sessions revealed both positive and negative perceptions. Positive comments outnumbered negative comments by a ratio of three to one. Most of the positive student commentary was general in nature, expressing gratitude for the assistance, a fondness for the tutor, or social greetings. The general nature of student responses is not surprising given the age of students and the open-ended nature of the prompt to simply comment on the session. However, even within this unstructured environment, approximately $40 \%$ of students spontaneously indicated that they found the session to be helpful for their mathematics learning, and about a quarter of students identified specific learning outcomes of the session. For example, one student commented, "Good session-now I understand integers." Another noted, "Now I get irrational numbers and rational numbers." A smaller percentage of students made specific statements indicating they left the session feeling more confident in the material, as the following comments illustrate: "He made it seem so easy, because it is," and "It is easy once you learn it."

Student negative commentary about the tutoring sessions was far less frequent than positive commentary, but was often more specific in nature. The two most prevalent themes of negative response to tutoring were related to pacing of the sessions, and the desire for more explanation. Students who made comments about pacing were far more likely to say the session went too slow rather than too fast. Due to the general nature of much of the commentary, it was unclear whether this related primarily to the speed of connection or to the actual pedagogical pacing. However, some students did specifically articulate that too much time was spent on tutor explanation and not enough on student work. For example, one student noted, "He doesn't let me work out the problem even when he tells me to solve it on my own." Of students who did desire more explanation, there was a desire for greater clarity of explanation, as expressed by the following student: "This tutor was great, just needs to work on explaining a little bit more and showing his work more clearly.” 


\section{Findings and Discussion}

The findings of this study suggest that well-designed-and-implemented synchronous online mathematics tutoring may be an effective Tier 3 intervention for students in high-need settings who are struggling with mathematics. Our findings support the extant literature on online mathematics tutoring and provide further evidence that the strategy can be successful in improving mathematics achievement of underperforming middle school students when compared to their nontutored peers. Although the propensity score matched comparison analysis did not reveal a statistically significant difference in the adjusted means between tutored and nontutored students, within-group effect-size estimates indicated a large relative advantage for tutored students in School $1(d=+0.95$ for tutored versus $d=+0.24$ for nontutored students), and a large absolute gain for tutored students in School $2(d=+1.47)$. It is worth noting that these results were observed in a context where the schools were implementing a wellresourced and proven instructional model that addresses Tier 1 and Tier 2 RTI supports.

Tutor-described practices suggested good fidelity of implementation of the model and alignment with the literature. Almost all tutors discussed the use of formative assessments of student learning before, during, and after each session to guide the instruction provided in the session and set goals for future sessions. These findings are consistent with the goals of the program studied here as well as the literature on the benefits of systematic, ongoing progress monitoring as a core principle of effective remediation for students who struggle with mathematics (Fashola, 1998; Fuchs et al., 2011). Tutors described the delivery of guided practice to students, and many discussed the use of multiple explanations and representations of target concepts. These approaches described by tutors are consistent with literature in the field that links instructional explanations and representations with development of student mathematics understanding (Charalambos et al., 2011; Fuchs et al., 2011; Hiebert et al., 1997).

These qualitative findings point to some of the mechanisms at work behind the achievement results and suggest some specific directions for practice in online mathematics tutoring as a Tier 3 intervention. Specifically, these tutors described attending assiduously to student pre- and postdata to guide their instructional moves, and to providing multiple scaffolded opportunities for the students to engage with the mathematics at their individual levels. Session tutoring logs contained evidence of articulation of the student's postlesson content mastery; identification of the student's individual difficulties; descriptions of the student's learning behaviors; reflection on the student's mathematical understanding during the lesson; and recommendations for future teaching/learning. Online tutoring programs might consider incorporating specific prompts in each of these areas for tutors to respond to postsession, to help ensure all of these components are systematically addressed in each session.

Student commentary further supported the use of online mathematics tutoring that is data driven, individualized, and focused as a Tier 3 intervention for students who struggle. Although a great deal of the student postsession commentary was general in nature, it was overwhelmingly positive. More importantly, even within the context of a fairly unstructured prompt, some students identified specific learning outcomes of the sessions. This suggests that online mathematics tutoring that embeds consistent progress monitoring may engage students in thinking about their own mathematics learning as a process for enhancing achievement. A possible implication for practice is to consider how to include specific prompts for students to co-reflect on their learning with their online tutors. For example, online tutoring sessions might conclude with a prompt for students to identify what they learned that session and to explain how they know they learned this, providing students with the opportunity to think about their own mathematical understanding and the tutors with a window into student thinking.

Student perceptions of the pacing of online tutoring were mixed, which is possibly a function of the wide variety of reasons students may be assigned to a Tier 3 mathematics intervention. For example, for some students the achievement gap may be due to processing issues, and thus may require more explanation, while for others, attention-related issues may demand a faster pace. Furthermore, the 
expressed desire on the part of at least some students for more time to work out problems on their own resonates with the literature that describes tutoring effectiveness as a function of knowing how to employ strategic questioning before telling or giving answers to students (Donnelly, 2013). Similarly, a number of students expressed the desire for more autonomy in the online tutoring process, from the desire to move faster or slower, to work more independently or with more support, and to select a preferred tutor for each session. These are ideas that are valuable to consider in developing online tutoring platforms, particularly for middle school students who are typically in a location along the developmental trajectory that makes choice and control of learning especially desirable (Midgley, Anderman \& Hicks, 1995).

It is also important to note that students participating in this study were among the lowest performing students in two high-need rural middle schools with large numbers of students living in poverty. These are among the most underrepresented students in advanced STEM study and careers (Avery, 2013; Eick et al., 2007; Suresh, 2011) and the least likely to possess the mathematics confidence that motivates sustained engagement, persistence, and learning in the discipline (Perez, Cromley, \& Kaplan, 2014; Singh, Granville, \& Dika, 2002). Yet close to half the students indicated that they believed they learned during the tutoring session, a quarter identified a specific learning outcome, and some made detailed comments directly expressing their own increased confidence in their ability to understand and learn math. These findings suggest that for this particular population of students, the highly individualized and explicit nature of the tutoring support may have resulted in affective changes that are related to mathematics engagement and learning. The online nature of the program made this support available to students in isolated rural communities with comparatively limited access to resources for providing this type of focused, individualized instruction. Exploration of this theme and the impact of online tutoring programs that embed explicit schema-broadening instruction and systematic progress monitoring on students who have not traditionally succeeded with mathematics nor been well represented in higher level STEM study and careers is an area for further research.

\section{Limitations}

It should be noted that the study did not randomly assign equivalent students to the treatment condition, so it is not possible to definitively attribute outcomes to the tutoring program. Further, the generalizability of the results is limited in that both samples were comprised of very low-performing students from rural populations, and both schools were already engaged in a substantial school-wide mathematics instruction improvement initiative. Notwithstanding these caveats, this study provides promising evidence that a well-designed-and-implemented synchronous online tutoring program can augment the effectiveness of a robust, research-proven classroom model of mathematics instruction. 


\section{References}

Avery, L. M. (2013). Rural science education: Valuing local knowledge. Theory Into Practice 52(1), 2835.

Baker, J., Rieg, S., \& Clendaniel, T. (2006). An investigation of an after school math tutoring program: University tutors + elementary students = a successful partnership. Education, 127(2), 287-293.

Beal, C., Walles, R., Arroyo, I., \& Woolf, B. (2007). On-line tutoring for math achievement testing: A controlled evaluation. Journal of Interactive Online Learning, 6(1), 43-55.

Bray, M. (1999). The shadow education system: Private tutoring and its implications for planners. Fundamentals of Educational Planning Series, Number 61. Paper presented at the United Nations Educational, Scientific Cultural Organization, Paris International Institute for Educational Planning.

Bray, T. M. (2011). The challenge of shadow education: Private tutoring and its implications for policy makers in the European Union (pp. 1-78). European Commission.

Brown, A. L., Campione, J. C., Webber, L. S., \& McGilly, K. (1992). Interactive learning environments: A new look at assessment and instruction. In B. R. Gifford \& M. C. O’Connor (Eds.), Changing assessments: Alternative view of aptitude, achievement, and instruction (pp. 37-75). Boston: Kluwer Academic.

Burns, M. K., Senesac, B. V., \& Symington, T. (2003). The effectiveness of the hosts program in improving the reading achievement of children at-risk for reading failure. Literacy Research and Instruction, 43(2), 87-103.

Carnegie Learning. (2002). Results from Moore, OK. Cognitive Tutor Research Report OK-0101. Pittsburgh, PA.

Chappell, S., Nunnery, J., Pribesh, S., \& Hager, J. (2011). A meta-analysis of supplemental educational services (SES) provider effects on student achievement. Journal of Education for Students Placed at Risk, 16, 1-23.

Charalambos, C. Y., Hill, H. C., \& Ball, D. L. (2011). Prospective teachers' learning to provide instructional explanations: How does it look and what might it take? Journal of Mathematics Teacher Education, 14, 441-463.

Clark, A., \& Whetstone, P. (2014). The impact of an online tutoring program on mathematics achievement. The Journal of Educational Research, 107(6), 462-466.

Cohen, P., Kulik, J., \& Kulik, C. (1982). Educational outcomes of tutoring: A meta-analysis of findings. American Educational Research Journal, 19(2), 237-248.

Cooper, G., \& Sweller, J. (1987). Effects of schema acquisition and rule automation on mathematical problem solving transfer. Journal of Educational Psychology, 79, 347-362.

Donnelly, R. (2013). The role of the PBL tutor within blended academic development. Innovations in Education and Teaching International, 50(2), 133-143. 
Eick, C. J., Ewald, M. L., Richardson, V. B., \& Anderson, K. (2007). Building a leadership network supporting science education reform in rural east Alabama. Science Educator 16(1), 8-12.

eSchool News. (2009). Online tutoring program enhances students'skills. Retrieved online from http://www.eschoolnews.com/2009/06/08/online-tutoring-program-enhances-students-skills

Fashola, O. (1998). Building effective afterschool programs. Thousand Oaks, CA: Corwin Press.

Fuchs, L. S., Powell, S. R., Seethaler, P. M., Cirina, P. T., Fletcher, J. M., Fuchs, D., \& Hamlett, C. L. (2011). The development of arithmetic and word-problem skill among students with mathematics disability. In J. M. Kauffman, \& D. P. Hallahan (Eds.), Handbook of special education (pp. 703715). New York: Routledge.

Gick, M. L., \& Holyoake, K. L. (1983). Schema induction and analogical transfer. Cognitive Psychology, $15,1-8$.

Gordon, E. (2003). Looking beyond the stereotypes: Ensuring the true potential of tutoring. Phi Delta Kappan, 84(6), 456-459.

Guo, S., \& Fraser, M. W. (2010). Propensity score analysis: Statistical methods and applications. Thousand Oaks, CA: SAGE Publications.

Hiebert, J., Carpenter, T., Fennema, E., Fuson, K., Wearne, D., Murray, H., ... Human, P. (1997). Making sense: Teaching and learning mathematics with understanding. Portsmouth, NH: Heinemann.

Huang, M. H. (2013). After-school tutoring and the distribution of student performance. Comparative Education Review, 57(4), 689-710.

Koerwer, S. (2007). ThinkingStorm: The ABCs of online tutoring. Information Today, July/August 2007.

Kroesbergen, E. H., \& Van Luit, J. E. H. (2003). Mathematics interventions for children with special needs: A meta-analysis. Remedial and Special Education, 24, 97-114.

Kulik, J. A. (2003). Effects of using instructional technology in elementary and secondary schools: What controlled evaluation studies say. SRI project Number P10446.001. Arlington, VA: SRI International.

Leedy, P., \& Ormrod, J. (2010). Practical research: Planning and design (9th ed.). Upper Saddle River, NJ: Pearson Education.

Maloy, R., Razzaq, L., \& Edwards, S. (2014). Learning by choosing: Fourth graders use of an online multimedia tutoring system for math problem solving. Journal of Interactive Learning Research, 25(1), 51-64.

Midgley, C., Anderman, E., \& Hicks, L. (1995). Differences between elementary and middle school teachers and students: A goal theory approach. Journal of Early Adolescence, 15, 90-113.

Morris, S., \& DeShon, R. (2002). Combining effect-size estimates in meta-analysis with repeated measures and independent-group designs. Psychological Methods, 7, 105-125. 
Nguyen, D., \& Kulm, G. (2005). Using web-based practice to enhance mathematics learning and achievement. Journal of Interactive Online Learning, 3, 1-16.

Nunnery, J., Chappell, S., \& Arnold, P. (2013). A meta-analysis of a cooperative learning model's effects on student achievement in mathematics. Cypriot Journal of Educational Sciences, 8(1), 34-38.

O’Connor, R. E., \& Sanchez, V. (2011). Responsiveness to intervention models for reducing reading difficulties and identifying learning disability. In J. M. Kauffman \& D. P. Hallahan (Eds.), Handbook of special education (pp. 703-715). New York: Routledge.

Patton, M. (2002). Qualitative research and evaluation methods. Thousand Oaks, CA: Sage Publications.

Perez, T., Cromley, J., \& Kaplan, A. (2014). The role of identity development, values, and costs in college STEM retention. Journal of Educational Psychology, 106, 315-329.

Ritter, G., Barnett, J., Denny, G., \& Albin, G. (2009). The effectiveness of volunteer tutoring programs for elementary and middle school students: A meta-analysis. Review of Educational Research, 79(1), 3-38.

Rothman, T., \& Henderson, M. (2011). Do school-based tutoring programs significantly improve student performance on standardized tests? RMLE Online: Research in Middle Level Education, 34(6), 110.

Sanderson, D. (2003). Setting up a successful after school tutorial program: One district’s journey. Reading Improvement, 40(1), 13-20.

Shenton, A. K. (2004). Strategies for ensuring trustworthiness in qualitative research projects. Education for Information, 22, 63-75.

Singh, K., Granville, M., \& Dika, S. (2002). Mathematics and science achievement: Effects of motivation, interest, and academic engagement. The Journal of Educational Research 95(6), 323-332.

Slavin, R. E. (1995). Cooperative learning: Theory, research, and practice. Boston, MA: Allyn and Bacon.

Suresh, S. (2011, January 7). The changing science, technology, engineering and mathematics (STEM) workforce. Paper presented at the President's Council of Advisors on Science and Technology, Washington, DC. Retrieved from http://www.todaysengineer.org/2011/Mar/STEMWorkforce.asp

Topping, K. (2000). Tutoring. Brussels, Belgium: International Academy of Education.

Vasquez, E., III, \& Slocum, T. (2012). Evaluation of synchronous online tutoring for students at risk of reading failure. Exceptional Children, 78(2), 221-235.

Virginia Department of Education. (2012). Virginia standard of learning assessments: Technical report. 2011-2012 Administration cycle. Richmond, VA: Author.

Wasik, B. (1998). Using volunteers as reading tutors: Guidelines for successful practices. Reading Teacher, 51(7), 562-570.

Zhang, Y., \& Wildemuth, B. M. (2009). Qualitative analysis of content. In B. M. Wildemuth (Ed.), Applications of social research methods to questions in information and library science (pp. 308319). Westport, CT: Libraries Unlimited. 


\section{Appendix A}

Table A1

Codebook for Student Tutoring Session Comments

\begin{tabular}{|c|c|c|}
\hline Category & Codes & Examples \\
\hline $\begin{array}{l}\text { Social } \\
\text { interaction } \\
\text { with tutor }\end{array}$ & $\begin{array}{l}\text { 1. Statements expressing thanks } \\
\text { for the session } \\
\text { 2. Statements expressing a general } \\
\text { positive attribution to the } \\
\text { session or tutor } \\
\text { 3. Social greetings }\end{array}$ & $\begin{array}{l}\text { 1. “Thanks for working with me.” } \\
\text { 2. “I love your teaching.” } \\
\text { 3. “Talk to you on Tuesday.” }\end{array}$ \\
\hline $\begin{array}{l}\text { Learning } \\
\text { benefits }\end{array}$ & $\begin{array}{l}\text { 1. Statements indicating the } \\
\text { student found the tutor to be } \\
\text { helpful to them } \\
\text { 2. Statements that the student } \\
\text { constructed a specific } \\
\text { mathematical understanding } \\
\text { 3. Statements indicating student } \\
\text { left session feeling confident } \\
\text { about material } \\
\text { 4. Statements that the student liked } \\
\text { the website or tools }\end{array}$ & $\begin{array}{l}\text { 1. "He worked with me really well. He was nice } \\
\text { and helped me a lot." } \\
\text { 2. "Good session I now understand integers." } \\
\text { 3. "Now I get irrational number and rational } \\
\text { numbers." } \\
\text { 4. "He made it seem so easy, because it is" } \\
\text { 5. "I like the white board." }\end{array}$ \\
\hline $\begin{array}{l}\text { Learning } \\
\text { challenges }\end{array}$ & $\begin{array}{l}\text { 1. Pacing is too slow } \\
\text { 2. Pacing is too fast } \\
\text { 3. Desired more } \\
\text { explanation/clarification } \\
\text { 4. Desired more active } \\
\text { participation } \\
\text { 5. Problems with website and/or } \\
\text { connectivity }\end{array}$ & $\begin{array}{l}\text { 1. "Very slow, pick up the pace." } \\
\text { 2. "I feel like this is helping me but I also feel } \\
\text { like my tutor rushes me.” } \\
\text { 3. "The tutor was great, just needs to work on } \\
\text { explaining a little bit more, and showing his } \\
\text { work more clearly.” } \\
\text { 4. "It was good but he needs to let me do some } \\
\text { work by myself.” } \\
\text { 5. "At one point the thing didn't let me type } \\
\text { that’s why I took so long.” }\end{array}$ \\
\hline
\end{tabular}


Table A2

Codebook for Analysis of Online Math Tutor Logs

\begin{tabular}{|c|c|c|}
\hline Categories & Codes & Illustrative language \\
\hline $\begin{array}{l}\text { Assessment of } \\
\text { student's prior } \\
\text { knowledge }\end{array}$ & 1. Analysis of pretest data & $\begin{array}{l}\text { 1. Posted the pretest questions for the student } \\
\text { to solve. The test consisted of } 10 \text { problems. } \\
\text { [Student] attempted } 8 \text { problems, and solved } \\
5 \text { of them correctly. Student was not } \\
\text { familiar with concept of Pythagorean } \\
\text { theorem. }\end{array}$ \\
\hline $\begin{array}{l}\text { Online tutoring } \\
\text { interventions to } \\
\text { support student } \\
\text { understanding }\end{array}$ & $\begin{array}{l}\text { 1. Accessing prior knowledge } \\
\text { 2. Modeling } \\
\text { 3. Explaining steps in } \\
\text { mathematical processes } \\
\text { 4. Pointing out student mistakes to } \\
\text { the student } \\
\text { 5. Providing scaffolding through } \\
\text { questioning or prompts }\end{array}$ & $\begin{array}{l}\text { 1. Started session by giving warm-up problem } \\
\text { on dividing decimals with whole number. } \\
\text { 2. Showed him how to multiply the decimal } \\
\text { number with example. } \\
\text { 3. Explained all the five steps to find the } \\
\text { square root of the irrational numbers. } \\
\text { 4. Another problem of similar kind was } \\
\text { worked by the student with minor mistakes, } \\
\text { which she corrected on tutor's advice. } \\
\text { 5. Tutor helped the student by providing hints } \\
\text { to get the right answer. }\end{array}$ \\
\hline $\begin{array}{l}\text { Tutor reflection } \\
\text { on student } \\
\text { learning }\end{array}$ & $\begin{array}{l}\text { 1. Articulation of student's } \\
\text { postlesson content mastery } \\
\text { 2. Identification of student } \\
\text { difficulties, mathematics } \\
\text { 3. Identification of technological } \\
\text { issues impacting learning } \\
\text { 4. Description of student learning } \\
\text { behaviors } \\
\text { 5. Reflection on student } \\
\text { mathematical understanding } \\
\text { during lesson } \\
\text { 6. Recommendations for future } \\
\text { teaching/learning }\end{array}$ & $\begin{array}{l}\text { 1. Attempted eight problems and solved five of } \\
\text { them correctly. He scored } 50 \% \text { in the } \\
\text { session. } \\
\text { 2. The student faced difficulty in multiplying } \\
\text { and adding the numbers. } \\
\text { 3. The student struggled with writing on the } \\
\text { whiteboard. } \\
\text { 4. The student struggled with multiplying the } \\
\text { decimals, but corrected himself and was fast } \\
\text { while learning. } \\
\text { 5. Student was able to translate the given } \\
\text { image and could reflect the image over } \\
\text { different axis on the coordinate plane with } \\
\text { ease. } \\
\text { 6. He needs more practice in multiplication of } \\
\text { fractions. }\end{array}$ \\
\hline
\end{tabular}

